\title{
주기변화에 따른 $\mathrm{RC}$ 서보모터 회전범위 비교실험
}

\section{The Comparison Experiment of Rotation Range of RC Servo Motors According to change of a Periods}

\author{
차 영 엽* \\ (Young-Youp $\mathrm{Cha}^{1}$ ) \\ ${ }^{1}$ Wonkwang University
}

\begin{abstract}
RC servos are electro-mechanical devices that respond to a control signal, which instructs them to move their output shaft to a certain position. A servo is normally plugged into a radio receiver with a three pin connector. The three wires are a power (usually $4.8 \mathrm{~V}$ to $6.0 \mathrm{~V}$ ), a ground, and a signal wire. The signal wire carries a PWM (Pulse-Width Modulation) signal consisting of a $1-2 \mathrm{msec}$ pulse repeated 50 times a second. A $1.5 \mathrm{msec}$ pulse will tell the servo to move to its output shaft to the center position, 0 degrees. For a servo with a 180 degree of motion, a $1 \mathrm{msec}$ pulse will move the servo to -90 degrees, and a $2 \mathrm{msec}$ pulse will move the servo to +90 degrees. In order to development a humanoid robot, mechanical design, fixtures design, analysis of kinematics, implementation moving program, selection of RC servo motor and controller are required. This study was performed to experimentally compare the rotation range of RC servo motors according to change of a periods.
\end{abstract}

Keywords: RC servo motor, humanoid robot

\section{I. 서론}

휴머노이드 로봇을 위한 연구는 두 가지 영역으로 나눌 수 있다. 첫째는 2족 보행 및 메커니즘의 연구이고[1-3], 둘 째는 비전, 음성인식 등 센서기반 인공지능 연구이다. 1996 년을 시작으로 혼다의 아시모(Asimo)가 발표된 후 전 세계 적으로 자율형 휴머노이드 로봇 연구에 대한 관심이 고조 되었다. 현재 아이들의 장난감에서부터 어른들의 애완로봇 에 이르기까지 로봇은 우리 삶에 점점 더 가까워지고 있다.

이러한 휴머노이드 로봇에는 소형의 경우에 RC 서보모 터가 사용되고 있다. 산업계에서는 동력원으로 많이 사용되 는 $\mathrm{BLDC}$ 형의 서보모터를 간략히 서보모터로 부른다. 본래 서보(Servo)라는 말은 명령추종을 의미하는데, 산업계에서 사용되는 BLDC형 서보모터제어기 역시 펼스열에 의한 속 도위치 추종기능을 기본적으로 가지고 있다.

산업용 $\mathrm{BLDC}$ 형 모터이외에 모형비행기나 자동차 그리 고 휴머노이드 로봇에 소형 $\mathrm{RC}$ 서보모터가 사용되는데, 포 텐시오미터(potentiometer)를 이용해서 간단한 위치추종 기능 만을 가진다. 본 연구에서 다루고자 하는 서보모터는 $\mathrm{RC}$ 서보모터이다. 이러한 $\mathrm{RC}$ 서보모터는 구동이 쉬운데 그 이 유는 내부에 각도 피드백용 가변저항과 제어기가 내장되어 있기 때문이다. 따라서 RC 서보모터는 휴머노이드 로봇이 나 리모트 컨트롤용 기기 등에서 회전위치 제어를 간단하 게 수행할 때 주로 사용된다. RC 서보모터가 일반 $\mathrm{AC}$ 나

* 책임저자(Corresponding Author)

논문접수: 2011.7.9., 수정: 2011.9.2., 채택확정: 2011.9.15.

차영엽: 원광대학교 기계자동차공학부, 공업기술개발연구소 연구위원 (ggypcha@wonkwang.ac.kr)

※ 상기 논문은 제어·로봇 - 시스템학회 전북제주지부의 학술대회 에서 초안이 발표되었음
$\mathrm{DC}$ 모터와 다른 점은 회전만 하는 것이 아니라 명령에 따 라서 특정위치에서 각도를 유지할 수 있다. 일반적으로 RC 서보모터는 주기가 $12-26 \mathrm{~ms}$ 인 $1.5 \mathrm{~ms}$ 폭의 펄스를 가하면 모 터는 중앙(0도), $1.0 \mathrm{msec}$ 폭의 펄스를 가하면 모터는 -90 도, $2.0 \mathrm{msec}$ 폭의 펄스를 가하면 모터는 +90 도를 향한다. 그 이 외의 각도는 펄스폭을 줄이거나 늘려서 조절이 가능하다.

본 논문에서는 생활환경에서 인간과 같이 생활하며, 궁 극적으로 인간을 항상 이롭게 할 수 있는 휴머노이드 로봇 개발을 위한 RC 서보모터에 대해 기술한다. 휴머노이드 로 봇에 사용할 $\mathrm{RC}$ 서보모터의 주기변화에 따른 회전범위를 비교하고 성능을 실험하기 위하여 엔코더와 카운터를 이용 하여 여러 종류의 RC 서보모터의 선형성과 회전범위를 실 험하였다.

\section{RC 서보모Eㅓㅓㄴ}

휴머노이드 로봇에서 사용되는 $\mathrm{RC}$ 서보모터는 로봇의 관절을 움직이는 사람의 근육 역할을 한다. 전동카나 수상 요트 둥에서는 바퀴나 조향타를 회전시키기 위하여 사용되 고 바퀴의 구동이나 추진력은 다른 $\mathrm{DC}$ 모터 등을 이용하 기 때문에 RC 서보모터에는 큰 힘이 요구되지 않았다. 그 러나 최근에는 휴머노이드 로봇이 각광을 받기 시작하면서 로봇을 움직이기 위한 동력원으로 RC 서보모터를 사용한 후로 기존의 크기나 중량의 중요성과 함께 큰 토크가 요구 된다.

$\mathrm{RC}$ 서보모터 구동방식에는 아나로그와 디지털 방식이 있는데 이들의 가장 큰 차이는 토크를 견디어 자세를 유지 하는 회로구성의 차이이다. 아나로그 방식은 예전부터 사용 해온 방식으로 RC 서보모터 전용으로 만들어진 모터제어 용 IC를 사용하고, 계속적으로 입력을 가하여야 한다. 이러 
한 아나로그 $\mathrm{RC}$ 서보모터의 장점은 가격이 싸다는 것이고 단점은 정밀도와 재현성이 좋지 않다는 것이다. 최근에 많 이 사용되는 디지털 방식은 마이크로컨트롤러와 전용 $\mathrm{IC}$ 로 구성되고 아나로그 방식에 비하여 토크가 크고, 입력을 한 번만 주어도 해당위치에서 정지해 있을 수 있다.

결과적으로 이러한 두 방식의 가장 큰 차이점은 입력 방 식과 더불어 토크의 크기인데 이는 하중을 견디어 자세를 유지하는 힘이다. RC 서보모터의 출력축에 외부로부터 힘 이 가해졌을 때 외력에 대하여 위치를 유지하려고 하는 힘 은 디지털이 더 강하다. RC 서보모터를 구동할 때 서보모 터에 전달되는 신호주기는 $12-26 \mathrm{msec}$ 이고 각 회사마다 약 간의 차이가 있다. $\mathrm{RC}$ 서보모터에 미소한 어긋남이 발생 하였을 때, 이 정도의 신호주기라면 곧바로 원래대로 되돌 리기는 어렵기 때문에 외부로부터 가해지는 힘에 밀리게 된다. 이를 개선하기 위하여 디지털 서보에서는 아나로그 서보보다 짧은 $1-5 \mathrm{~ms}$ 의 동작주기로 하여 외력에 대하여 빨 리 반응할 수 있도록 한 것이다.

$\mathrm{RC}$ 서보모터에서 입력신호는 펄스폭변조(PWM)와 디지 털 코드 즉 커멘드 방식이 있다. 여기서 펄스폭 변조는 단 어 자체의 엄밀한 의미와는 다르다. 절대값 펄스폭에 의하 여 제어되는 것이지 펄스폭 변조된 듀티비에 의하여 동작 하는 것이 아니기 때문이다. 이에 비하여 디지털 코드 방식 은 시리얼 방식이라고도 하뎌 휴머노이드 로봇용 디지털 서보에서 사용되고 있으며 점차 용도가 넓어지고 있다.

$\mathrm{RC}$ 서보모터에서 모터축의 회전을 $1 / 100-1 / 1000$ 로 감속 하여 출력축에 전달하는 기어는 4-6단의 평기어를 겹친 기 어 트레인을 사용한다. RC 서보모터의 경우에 예전에는 모 터 자체의 중량이 중요하여 기어의 재료로 수지인 플라스 틱이 사용되었으나 최근에는 내구성과 출력 토크를 크게 하기 위하여 알루미늠, 티타늄, 브래스, 철 등의 메탈기어가 사용되고 있다.

서보모터에는 3 가닥 혹은 4 가닥의 선이 있는데, 본체에 커넥터가 있어 접속할 수 있게 되어 있다. 선의 수가 3가닥 인 경우는 전원에 연결된 플러스와 마이너스의 2 가닥, 서보 모터를 움직이는 신호를 보내는 1가닥으로 총 3 가닥이 된 다. 4 가닥의 경우는 신호융 선이 2 가닥이다. RC의 경우는 3 선으로 통일되어 그 끝의 커넥터에는 거의 호환성이 있는 데, 선의 배색은 회사에 따라 차이가 있다.

PWM 방식에서는 많은 서보모터를 사용하는 경우, 컨트 롤러나 수신기로부터 각 서보모터에 각각 3 가닥의 배선이 필요하다. 또 $\mathrm{PWM}$ 방식에서는 서보모터에 위치지령으로 내리게 되는 펄스는, 정확하고 지터(펄스폭의 흔들림)가 없 는 것이 좋은데, 이를 마이크로컨트롤러로 만드는 것은 쉽 지 않고, 노이즈도 받기 쉬워서 로봇용에서는 커맨드방식이 라 불리는 방식이 늘고 있다. 이는 50 도나 0 도 등의 지령각 도의 수치를 코드화하고, 시리얼데이터로서 서보모터에 전 송한다. 일반적으로 코드에 포함되는 서보모터별로 설정된 $\mathrm{ID}$ 로 서보모터를 식별한다.

커맨드방식에서는 각 서보모터로의 배선은 모배선(3, 4가 닥)에서 가까운 곳으로 분기하는 멀티드롭 접속이나, 서보 모터 사이를 복잡하게 연결하는 디지 체인접속이 가능하다.
코드는 기본적으로 $\mathrm{PC}$ 등의 디지털기기에서 사용되는 16진 수 $\mathrm{ASCII}$ 코드로 구성되므로, $\mathrm{PC}$ 친화적 시스템이라고 할 수 있다. PWM 방식과 같이 각도위치뿐 아니라 스피드 등 의 세밀한 움직입을 서보모터에 보낼 수 있고, 서보모터 내 부의 정보(실제위치, 부하, 온도 등)를 받을 수 있는 것도 있다. 특히 로봇에서는 서보모터를 탈력(프리상태)시켜 손 으로 움직이고, 그 위치를 컨트롤러에 입력하는 기능이 편 리하다[4].

\section{RC 서보모터 비교실험}

표 1은 $\mathrm{SKC}$ 사와 $\mathrm{Hitec}$ 사 모터들의 종류별 그림과 주요 한 사양이 나와 있다[5,6]. 모터 크기는 각각 조금씩 차이가 있으며 각 제품의 특징도 나와 있다. 여기서 보면, 토크와 전압인가 범위도 차이가 있다. Hitec사는 모든 실헙 과정을 거쳐 다양한 사양들을 제시한다. 하지만 $\mathrm{SKC}$ 신창모터는 간단한 토크, 초당 속도, 사이즈 등 기본 적인 것 외에는 상세한 사양은 자료가 충분하지 못했다.

그립 1은 $\mathrm{RC}$ 서보 모터 실헙 구성도이다. 각 제조사별 모델별 RC 서보모터 성능을 비교하기 위하여 인크리멘탈 엔코더와 MMC servo controller를 활용하여 회전 각도를 측 정하였다. 엔코더에 플렉시블 커플링을 이용하여 RC 서보 모터에 연결하여, $\mathrm{RC}$ 서보모터 회전각에 대한 엔코더 값을 읽어 들여 명령에 따른 회전각의 선형성과 주기시간에 따 른 회전범위 그리고 펄스폭에 따른 회전각을 측정하였다.

실험 순서는 다음과 같다. $\mathrm{PC}$ 에서 $\mathrm{RC}$ 서보모터 구동 프 로그램을 컴파일하여 자체 제작한 펄스 생성 보드인 ATmega128에 다운로드한다[7]. ATmega128에 다운로드 된 프로그램에 의해 $\mathrm{RC}$ 서보모터가 회전하고, $\mathrm{RC}$ 서보모터는

\section{표 1. $\mathrm{RC}$ 서보모터 사양.}

Table 1. RC servo motor specification.

\begin{tabular}{|c|c|c|c|c|}
\hline & & & \\
& SKC & HITEC & HITEC & HITEC \\
\hline 제조사 & SDS-701M & HS-5645MG & HS-5945MG & HSR-5995TG \\
\hline name & SD- & & \\
\hline Voltage & $4.8 \sim 5.5$ & $4.8 \sim 6.0$ & $4.8 \sim 6.0$ & $4.8 \sim 7.4$ \\
\hline Torque & $7.5 \mathrm{~kg} . \mathrm{cm}$ & $10.3 \mathrm{~kg} . \mathrm{cm}$ & $11.0 \mathrm{~kg} . \mathrm{cm}$ & $24.0 \mathrm{~kg} . \mathrm{cm}$ \\
\hline Speed & $0.17 \mathrm{sec} / 60^{\circ}$ & $0.23 \mathrm{sec} / 60^{\circ}$ & $0.16 \mathrm{sec} / 60^{\circ}$ & $0.15 \mathrm{sec} / 60^{\circ}$ \\
\hline Dimension & $41 \times 20 \times 41 \mathrm{~mm}$ & $40.6 \times 19.8 \times 37.8 \mathrm{~mm}$ & $39.4 \times 20 \times 37.8 \mathrm{~mm}$ & $40 \times 20 \times 37 \mathrm{~mm}$ \\
\hline
\end{tabular}

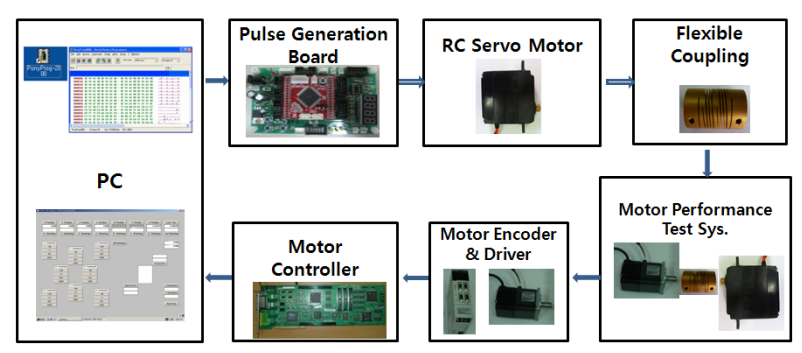

그립 1. RC 서보모터 실험순서.

Fig. 1. Experimental sequence of $\mathrm{RC}$ servo motor. 


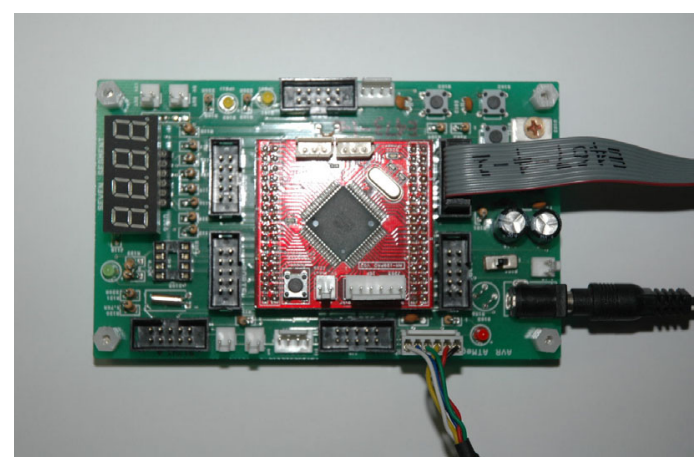

(a)

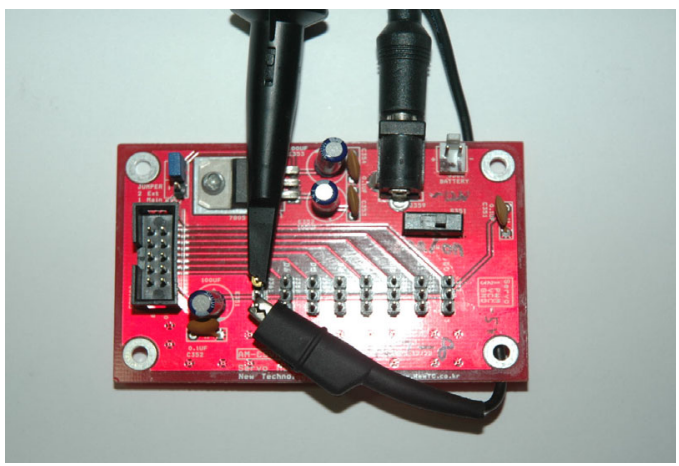

(b)

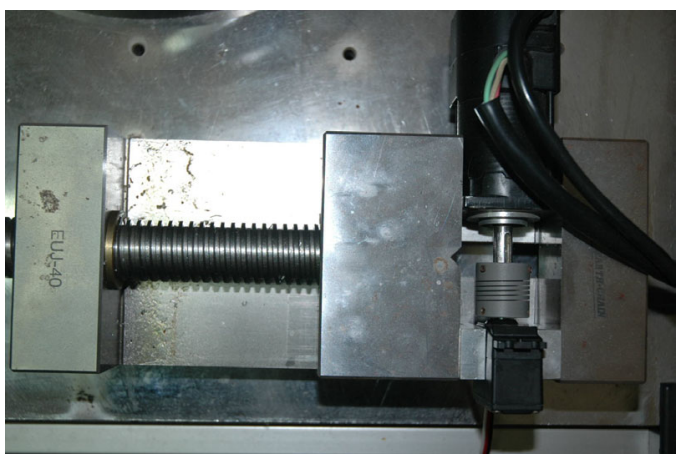

(c)

그림 2. ATmega128 보드(a), RC 서보모터 콘트롤러(b), RC 서 보모터 실헙장치(c).

Fig. 2. ATmega128 board(a), RC servo motor controller(b), and experimental setup for RC servo motor(c).

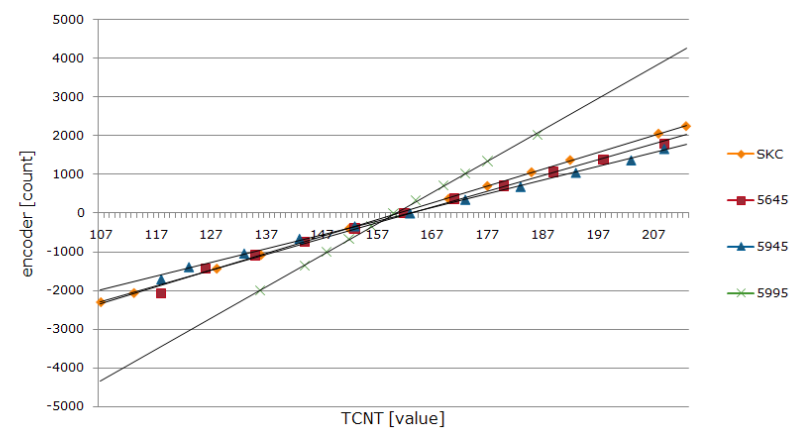

그림 3. 각각의 RC 서보모터에서 TCNT 값에 따른 엔코더 카운 트 그래프.

Fig. 3. Encoder count graph due to TCNT value in RC servo motors.

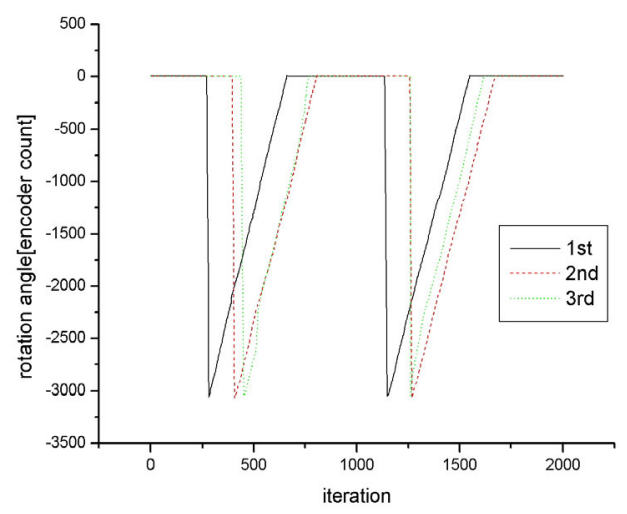

(a) $8 \mathrm{msec}$

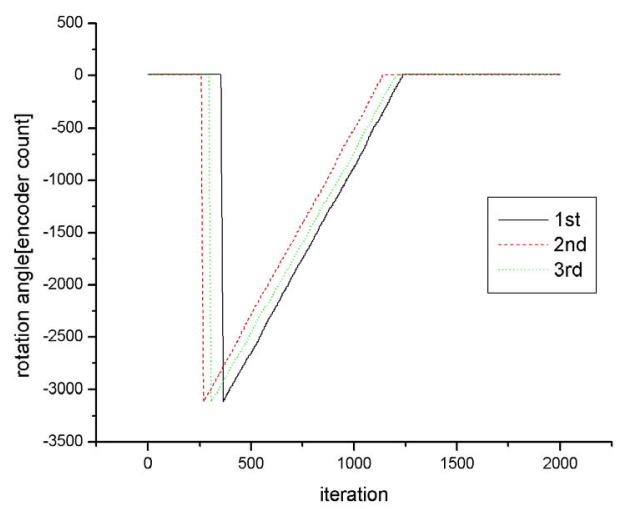

(b) $18 \mathrm{msec}$

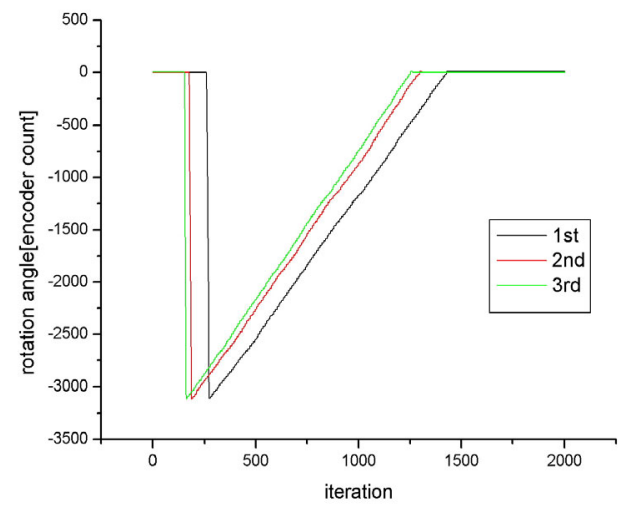

(c) $25 \mathrm{msec}$

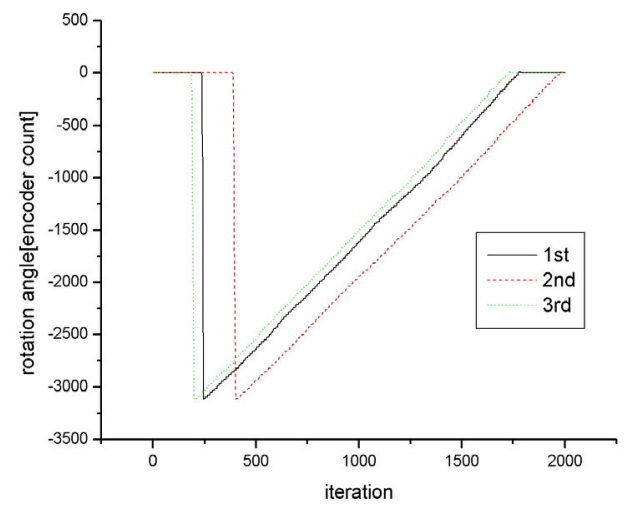

(d) $30 \mathrm{msec}$

그림 4. 펄스폭을 $0 \mathrm{msec}$ 에서 $3 \mathrm{msec}$ 까지 순차적으로 증가시킨 경우 RC 서보모터 회전각.

Fig. 4. Rotation angles of RC servo motor when pulse width changes from 0 to $3 \mathrm{msec}$. 


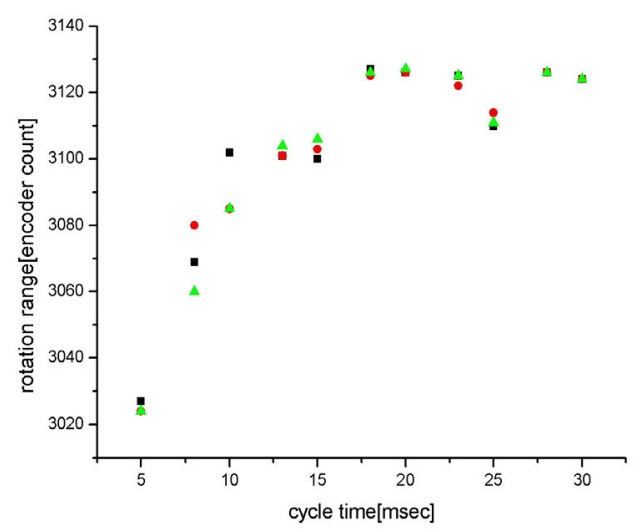

그림 5. Futaba S9452 RC 서보모터의 주기시간에 따른 회전범 위의 변화.

Fig. 5. Variation of rotation ranges due to cycle times of Futaba S9452 RC servo motor.

풀렉시블 커플링에 의해 연결된 서보모터(삼성 DC Brushless Servo Motor, CSM-01BB1ANT3)의 엔코더(8192pulse/rev)도 같이 회전하고, 그 신호가 모터 드라이버(삼성 DC Brushless Servo Driver, FARA SERVO CSDJ-01BX1)를 통하여 모터 컨 트롤러(삼성 로크웰사 MMC-BDPV81PNA) 보드로 전달되어 MMC Manager FP39 DDL로 연결된 휴먼 인터페이스 프로 그램에 의해 회전각도가 Counter 값으로 변환된다[8]. 단, 플 렉시블 커플링으로 인한 오차는 미세하므로 무시한다.

그림 2는 실제 실험에 사용된 장비들을 보여주고 있다. 그립 2(a)는 RC 서보모터에 펄스를 인가하기 위하여 실험 실에서 자체적으로 제작한 ATmega128 마이크로컨트롤러 보드이고, 그립 2(b)는 RC 서보모터 콘트롤러, 그리고 그립 2(c)는 RC 서보보터가 플렉시블 커플링으로 엔코더와 연결 된 RC 서보모터 실험장치를 보여주고 있다.

그림 3은 ATmega128보드의 타이머 기능을 이용하여 RC 서보모터에 가해지는 펄스폭을 TCNT 값으로 변화시켜 회 전각을 제어한 후에 $\mathrm{MMC}$ Manager FP39를 이용하여 Encoder 값을 읽은 것을 나타낸 것이다. 실험에 사용된 모 든 $\mathrm{RC}$ 서보모터에 인가된 전압은 $5 \mathrm{~V}$ 로 하였다. 여기서 회 전범위가 가장 안정적이고 넓은 분포를 갖고 있는 것이 $\mathrm{SKC}$ 신창 모터이고 그 다음이 Hitec사의 HS-5995TG, $\mathrm{HS}-5645 \mathrm{MG}, \mathrm{HS}-5945 \mathrm{MG}$ 순서임을 알 수 있다. 결과적으로 $\mathrm{SKC}$ 신창 모터는 Hitec 모터보다 회전범위가 크고 펄스폭 변화와 회전각도 사이에 선형 관계가 성립됨을 확인 할 수 있고 오차 범위가 Hitec 모터보다 좁았다.

그립 4는 Futaba 사의 S9452[9] RC 서보모터의 주기시간 이 각각 $8 \mathrm{msec}, 18 \mathrm{msec}, 25 \mathrm{msec}, 30 \mathrm{msec}$ 일 때 펄스폭을 $0 \mathrm{msec}$ 에서 $3 \mathrm{msec}$ 까지 순차적으로 증가시킨 경우의 $\mathrm{RC}$ 서 보모터 회전각을 3 회 반복 실험하여 나타낸 것이다. $8 \mathrm{msec}$ 에서는 3 회 실험에서 선형성이 잘 유지되는 것처럼 보이지 만, 주기시간이 길어질수록 선형성이 나빠지는 것을 알 수 있다. 참고로 $30 \mathrm{msec}$ 인 경우에는 42 초 동안 회전이 이루어
졌다.

그립 5는 Futaba 사의 S9452 RC서보모터의 주기시간변 화에 따른 회전범위를 비교한 것이다. 여기서 보면 $20 \mathrm{msec}$ 근처에서 다른 값들보다 상대적으로 넓은 회전범위를 갖는 것을 알 수 있다. 또한 주기가 $30 \mathrm{msec}$ 범위에서는 회전범위 가 $20 \mathrm{msec}$ 인 경우와 비슷하게 유지되지만, $10 \mathrm{msec}$ 이하에 서 회전범위가 급격히 작아지는 것을 알 수 있다. 제품 카 탈로그에서는 펄스폭이 $1.52 \mathrm{msec}$ 에서 중심(neutral)에 위치하 고 $1.9 \mathrm{msec}$ 에서 반시계방향으로 회전한다고 되어있는데, 실 험에서는 펄스폭이 $0.8-2.2 \mathrm{msec}$ 에서 동작이 되는 것을 알 수 있었다.

\section{IV. 결론}

본 논문에서는 생활환경에서 인간과 같이 생활하며, 궁 극적으로 인간을 항상 이롭게 할 수 있는 휴머노이드 로봇 개발을 위한 RC 서보모터에 대해 기술하였다. 휴머노이드 로봇에 사용하는 여러 종류의 $\mathrm{RC}$ 서보모터를 비교하고 성 능실험을 위하여 엔코더와 카운터를 이용하여 RC 서보모 터의 주기에 따른 선형성과 회전범위 그리고 펄스폭 변화 에 따른 회전각 변화를 실험하였다.

\section{참고문헌}

[1] H. G. Gang, "A study on modeling and development of biped walking robot," Master Thesis in Wonkwnag University (in Korean), 2004.

[2] D. W. Yu, "The design of a biped walking robot using DC Servo motor," Master Thesis in Wonkwnag University (in Korean), 2006.

[3] J. S. Gong, "A Study on the posture control of a humanoid robot," Journal of Control, Automation, and Systems Engineering (in Korean), vol. 11, no. 1, pp. 78-79, 2005.

[4] R/C \& Robot Magazine, Dec. 2008.

[5] Hitec Homepage, www.hitecrcd.co.kr

[6] SKC Shinchang Homepage, www.skcshinchang.kr

[7] Atmel Homepage, www.atmel.com

[8] Rockwell Automation Homepage, www.rockwellautoma tion.co.kr

[9] Futaba Homepage, www.futaba-rc.com

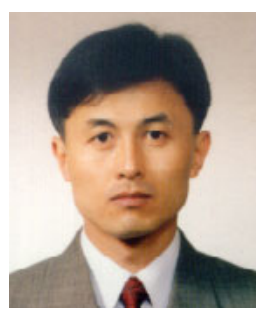

\section{차 영 엽}

1984년 부산대 기계공학과 졸업. 1987 년 한국과학기술원 생산공학과 석사. 1995년 한국과학기술원 정밀공학과 박 사. 1995년 현재 원광대학교 기계자동 차공학부 교수. 관심분야는 로봇과 영 상처리. 